\section{Sickness benefit claims due to mental disorders in Brazil: associations in a population-based study}

\author{
Benefícios auxílio-doença devido a transtornos \\ mentais no Brasil: associações em um estudo \\ de base-populacional
}

Anadergh Barbosa-Branco 1,2

Ute Bültmann ${ }^{3}$

Ivan Steenstra ${ }^{1}$

\footnotetext{
${ }^{1}$ Institute for Work and Health, Toronto, Canada. 2 Departamento de Saúde Coletiva, Universidade de Brasília, Brasília, Brasil. 3 Department of Health Sciences, Community \& Occupational Medicine, University Medical Center Groningen, Groningen, Netherlands.

Correspondence A. Barbosa-Branco Institute for Work and Health.

22 Cedar Springs Grove, Toronto, ON - M3H 5L2, Canada.

anadergh@hotmail.com
}

\begin{abstract}
This study aims to determine the prevalence and duration of sickness benefit claims due to mental disorders and their association with economic activity, sex, age, work-relatedness and income replacement using a population-based study of sickness benefit claims (> 15 days) due to mental disorders in Brazil carried out in 2008. The prevalence of mental disorders was 45.1 claims per 10,000 workers. Prevalence and duration of sickness benefit claims due to mental disorder were higher and longer in workers aged over 40 years. Prevalence of claims was $73 \%$ higher in women but duration of sickness benefit claims was longer in men. Prevalence rates for claims differed widely according to economic activity, with sewage, residential care and programming and broadcasting activities showing the highest rates. Claims were deemed to be work-related in 8.5\% of cases with mental disorder showing low work-relatedness in Brazil. A wide variation of prevalence and duration between age, economic activity and work-relatedness was observed, suggesting that working conditions are a more important factor in mental disorder work disability than previously assumed.
\end{abstract}

Mental Disorders; Social Security; Depression; Work

\section{Background}

Mental disorders are one of the three major causes of work absence due to sickness and work disability. The number of sickness benefit claims due to mental disorders has increased in recent years and the burden of illness is reflected in major economic and social losses 1,2,3,4,5. Claimants with mental disorders stay on benefits for longer than those who make claims due to other diseases 1,6 and the risk of sickness benefit becoming a disability pension is greater among this group 2,7 .

Establishing an epidemiological panorama for sickness absence due to mental disorders is a challenge, since different research approaches, coverage and classification systems are used 2,8 . In the Netherlands, the 12-month incidence of sickness absence due to mental disorders lasting more than 28 days varied from $2 \%$ to $2.7 \% 4$. Similar rates $(2.5 \%)$ have been observed in Norway but with an earlier inception point (> 14 days) 9 . A recent review 8 based on 243 international studies of one-year prevalence of mental health diagnoses and disability rates presented prevalence rates varying from $0.5 \%$ for schizophrenia to $9.1 \%$ for personality disorders. Alcohol abuse/ dependence and major depressive disorders showed a prevalence of $6 \%$ and $5 \%$, respectively. Schizophrenia and bipolar disorder showed the highest disability rates. Rates in Asian countries appear to be lower than in European countries for all mental disorders ${ }^{8}$. 
Among mental disorders, depression is often reported to be the main cause of sickness absence 8,10,11, except in France, where anxiety disorders have shown to be the main cause 12 . This difference could be due to the age distribution of these studies, since depression seems to be more frequent among older workers ( $>40)$ and anxiety disorders are greater among the younger contingent $(<40) 13$.

Several risk factors related to sickness absence claims due to mental disorders have been reported in the literature, such as female gender $1,3,4,6,10,12,14,15,16$, older age 2,4,6,16 and lower socioeconomic status/income, especially in countries with large socioeconomic inequalities 15. Other reported factors associated with sickness absence due to mental disorders are marital status 3 , high job strain, low job autonomy $3,14,17$, emotional demands, working with people 4 , low social support 14 , job insecurity, violence, low educational level 3 and occupation 12,13,16. Sectors such as education, financial services and healthcare showed a high incidence of mental disorders 4 , and the highest prevalence of fatigue and psychological distress has been found in occupations such as controllers, electro-technical machinery testers and headwaiters 18 .

Studies in Brazil on prevalence of mental disorders in the adult population were summarized in a recent review which showed that rates for mental disorders vary from $20 \%$ to $56 \%$, with higher rates among females and significant differences between major urban centres. Several work categories have been studied and prevalence of mental disorders was shown to be particularly high among teachers, rural workers, nurses, community health agents and drivers. The most prevalent mental disorder groups highlighted by the study were anxiety disorders, mood disorders (mainly depression), somatoform disorders and use of alcohol; although it should be noted that different diagnostic methods were used. Disorders due to the use of alcohol were three to four times more prevalent among males and this diagnosis had the highest prevalence rate ratios between sexes 19 .

Owing to the high rates of sickness absence and work disability due to mental disorders, determining the association between these disorders and the working environment and working conditions is a challenge. In the context of workers' compensation, mental disorders do not tend to be regarded as highly work-related 20,21. Multifactorial risks and latent, chronic processes contribute to the difficulties in determining the work-relatedness of mental disorders. However, recent reviews of social factors at work and the risk of depression have shown that other factors besides well-known ones such as gender, age, income, education level, unemployment and marital status are also highly associated with depression 22,23. The authors point out that work-related psychosocial factors such as high demand with low decision latitude (job strain) was highly associated to subsequent depression, together with effort-reward imbalance, organizational injustice 22,23, undesirable work events and bullying 22 . Some countries, such as Canada, restrict allowable work-related factors that may lead to specific conditions/diagnoses for workers' compensation claims such as mental disorder 20,21, while other countries, such as Great Britain, the Netherlands and Norway make no distinction between workrelated and non-work-related benefit 1,4,6.

This study aims to determine the prevalence and duration of sickness benefit claims due to mental and behavioural disorders and examines their association with economic activity, sex, age, work-relatedness and income replacement sickness benefit claims.

\section{Material and methods}

\section{The Brazilian sickness benefit scheme}

All Brazilian employed workers have mandatory insurance coverage, provided by the National Social Security Institute, an independent arm of the Brazilian Ministry of Social Security (Ministério da Previdência Social). In Brazil, "employed worker" is a legal term used to describe a worker with a registered work contract, normally in the private sector, under the "Consolidation of Labour Laws" 24.

The National Social Security Institute provides a wide range of non-work-related benefits, including maternity leave, retirement (by age, duration of contribution or non-work-related disability), and non-work-related sickness benefits. In addition, all employees are insured for workrelated disability. Insurance premiums are paid for by employers. Temporary disability (sickness benefit claim), regardless of work-relatedness, is generally granted for up to two years. After this time, if the worker is still unable to return to work, this benefit will be converted to a disability pension. All sickness benefit claims must be certified by a qualified doctor (médico auditor in Portuguese) after establishing the diagnosis. The first 15 days of absence (based on a doctor-certified diagnosis, International Classification of Diseases, 10th Revision - ICD-10) are paid by the employer, regardless of work-relatedness. Once the doctor confirms the absence as a temporary work disability, the National Social Security 
Institute pays the sickness benefit claim, regardless of whether the cause is work-related or not. Sickness benefits are only granted for temporary disabilities. The worker cannot be dismissed while on sickness benefit. In practice, however, workers are often dismissed upon their return to work in cases of sickness benefits that are not work-related. For work-related sickness benefits, the worker cannot be dismissed for at least one year after returning to work. Socioeconomic factors play a major role in a worker's decision to go on benefit and highlight the importance of accurately identifying work-relatedness of illnesses and injuries.

Work-related benefits are identified in three possible ways: (1) the employer completes a "work-related injury or disease communication" form; (2) work-relatedness of the claim is supported by epidemiological evidence; and (3) the National Social Security Institute doctor assesses the claim as work-related based on evidence presented by the claimant.

\section{Study population}

This is a population-based, national cohort study that includes all registered private sector jobs in Brazil. In 2008, the working-age population of the country was estimated at 99,500,202. Of these, $40 \%(39,652,510)$ had National Social Security Institute coverage. Our study population consisted of approximately $80 \%$ of employed insured workers $(32,590,239)$. The remaining $20 \%$ of insured workers were self-employed and temporary workers. The worker population is counted as the number of jobs, since one worker can have more than one job, especially in the education and health sectors. Although it is not possible to accurately quantify the number of workers, it is estimated that less than $10 \%$ have more than one job.

\section{Data sources}

This study used two main databases: (1) the National Benefits System (Sistema Único de Benefícios - SUB in Portuguese); and (2) the National Social Information Database (Cadastro Nacional de Informações Sociais - CNIS in Portuguese) both of which are part of the National Social Security Institute. The SUB database contains information on sickness benefit claims and other variables including age, clinical cause of disability (ICD-10 codes), sex, income, duration and work-relatedness (work-related or non-workrelated) and economic activity (Standard Industrial Classification of Economic Activities 2007 SIC. http://www.ons.gov.uk/ons/guide-method/ classifications/current-standard-classifications / standard-industrial-classification/index.html accessed on 05/Dec/2011). The SUB database was used to capture cases (i.e. numerator).

The CNIS database contains information on all insured workers in every private sector company. All new workers contracted or dismissed during the preceding month are entered into the system. We calculated the annual worker population by averaging all monthly reports during 2008. This database provided our population at risk (i.e. denominator). We used the two databases to calculate prevalence rates of sickness benefit claims due to mental disorders. The CNIS database also provides information on SIC, sex and age. The SIC is divided into four levels, 21 sections, 88 divisions and more than 700 classes with four and five digit codes. Our analysis was restricted to the divisional level. The Brazilian SIC-2007 follows the UK SIC-2007, the European NACE and the United Nations' ISIC. These classifications are consistent and follow the same codification.

\section{Case definition}

Each new sickness benefit claim in our study population, regardless of work-relatedness, granted by the National Social Security Institute between January 1st and December 31st 2008 was defined as a case. A worker receives only one benefit regardless of the number of jobs he or she has. All benefit claims were considered to be a new claim. Claim applications for the same diagnosis and within 60 days of the first return-to-work were considered to be a continuation of the previous claim, and only the original one was counted.

\section{Data analysis}

The cumulative prevalence of sickness benefit claims was calculated for the ICD-10 chapter Mental and Behavioural Disorders, SIC (division level), sex and age group ( $<20$ years; $20-29$ years; 30-39 years; 40 - 49 years; $50-59$ years; $\geq 60$ years, or dichotomized as $<40$ years and $\geq 40$ years). The numerator was defined as the number of sickness benefit claims due to mental disorders in 2008. The denominator was defined as the average number of workers at risk in 2008. Where applicable, standardized sex and age rates were calculated to compare sickness benefit rates by SIC, where total population was used as the standard. We computed the prevalence of work-related and non-work-related sickness benefit claims due to mental disorders. The cumulative prevalence rates are presented as number of cases per 10,000 workers per year. Unless otherwise stated, 
the prevalence rate ratio (PRR) was calculated by dividing the specific prevalence rate by the total prevalence rate.

Duration of sickness benefit claims is presented in days using measures as median and quartiles one and three (25\% and $75 \%)$.

\section{Results}

\section{Prevalence of sickness benefit claims}

In 2008, 147,105 sickness benefit claims due to mental disorders were granted to a population at risk of 32,590,239 workers, resulting in an age/ sex standardized rate of 44.9 claims per 10,000 workers. Our previous study showed that sickness benefit claims due to mental disorders represented $10.7 \%$ of the total sickness benefit claims granted during 2008 (Standard Industrial Classification of Economic Activities 2007 - SIC. http://www.ons.gov.uk/ons/guide-method/ classifications/current-standard-classifications/ standard-industrial-classification/index.html, accessed on 05/Dec/2011). Table 1 presents the prevalence rates of sickness benefit claims for mental disorders by SIC, work-relatedness, agespecific group and age/sex standardized rates. The SICs sewage, residential care and programming and broadcasting showed 5.3, 4.1 and 3.9 times more sickness benefit claims than the general population, respectively.

With respect to work-related claims (Table 1), the highest prevalence rate was observed among residential care workers, with a PRR of 11.6 when compared to all workers. This compares to the second highest prevalence rate found among programming and broadcasting workers, with a PRR of 2.4.

The PRR for non-work-related and workrelated claims showed considerable differences between each SIC. Activities such as residential care and financial services presented the highest ratio of work-related claims (PRR 3.6 and 3.8, respectively). Prevalence rates of sickness benefit claims due to mental disorders in Brazil increase with age, up to the age of 49 , and then start to decline. The increase between the 30 to 39 years and 40 to 49 years age groups was less than $5 \%$. In several SICs, the highest rates appeared in the 30 to 39 years age group. This pattern is different in programming and broadcasting workers, where rates peaked among young adults aged 20 to 29 years) and then declined (Table 1).

Table 2 shows the prevalence rates of sickness benefit claims classified by mental disorder, sex and age. The most common diagnostic group of mental disorders in both sexes was mood disor- ders (42.9\%), with females showing a PRR of 3.4 when compared to males. In comparing the rates of the first and the second highest ranked groups of mental disorders, the PRR among women (mood disorders - neurotic, stress related and somatoform disorders) was 2.8, while for men (mood disorders - psychoactive substances use) this ratio was 0.6 . Sickness benefit claims due to all mental disorders presented a similar age pattern in both sexes as well as for most ICD-10 codes of mental disorders. However, the diagnostic group of mental disorders due to psychoactive substances use (F10 to F19) showed higher rates for male workers throughout all ages, and in particular at younger ages (20 to 29 years) where men made 18.9 times more claims (Table 2).

\section{Duration of sickness benefit claims}

Table 3 presents results related to the duration of sickness benefit claims (median and quartiles one and three) according to ICD-10 group and sex, age and salary replacement. Duration of work absence due to mental disorders was longer in males [76 (47; 113 days)], older workers [74 (46; 110 days)], and workers with higher levels of salary replacement [72 (46; 108 days)] The duration of sickness benefit claims due to psychoactive substance use was longer in younger workers and those with lower levels of salary replacement.

Table 4 shows claims duration and prevalence by ICD-10 codes and dichotomous age group. Duration was longest for schizophrenia and unspecified nonorganic psychosis regardless of age. Depression was the most common diagnosis, regardless of age group. The older group ( $\geq 40$ years) showed higher prevalence and longer duration for mental disorders in general and for most specific mental disorders diagnoses, with the exception of mental disorders due to multiple drug use and use of other psychoactive substances (F19), use of alcohol (F10) and use of cocaine (F14).

The analysis of duration of sickness benefit claims by economic activity (Table 5) showed differences between SICs that varied by up to $62 \%$, where the greatest differences were in the $25 \%$ shorter claims (quartile one). This difference decreases as duration increases, varying up to $35 \%$ in quartile two and up to $26 \%$ in quartile three. The duration of claims was longest among construction, security and transport (air and land) workers. To obtain a better understanding of the association between SIC, prevalence and duration, we carried out further analysis of sickness benefit claims by SIC and ICD-group. This analysis evaluated the participation of the most prevalent ICD-group (F10-F19, F20-F29, F30-F39 and 
Table 1

Rates * of disability claims due to mental disorders according to economic activity **, sex, age, and work-relatedness. Brazil, 2008.

\begin{tabular}{|c|c|c|c|c|c|c|c|c|c|c|c|}
\hline \multirow[t]{2}{*}{ SIC 2007 division } & \multirow{2}{*}{$\begin{array}{l}\text { Total } \\
\text { claims }\end{array}$} & \multicolumn{3}{|c|}{ Sex/age adjusted } & \multirow{2}{*}{$\begin{array}{c}\text { NWR/WR } \\
\text { PRR }\end{array}$} & \multicolumn{6}{|c|}{ Age specific rate (years) } \\
\hline & & NWR & WR & Total & & $<20$ & $20-29$ & $30-39$ & $40-49$ & $50-59$ & $\geq 60$ \\
\hline 37 & 913 & 225.5 & 14.5 & 240.0 & 15.5 & 0.0 & 153.5 & 230.3 & 272.6 & 267.0 & 192.5 \\
\hline 87 & 1,645 & 144.4 & 39.9 & 184.3 & 3.6 & 31.0 & 143.8 & 241.3 & 228.6 & 190.3 & 103.0 \\
\hline 60 & 1,287 & 159.6 & 16.4 & 176.1 & 9.7 & 58.7 & 258.4 & 167.9 & 105.7 & 84.2 & 23.9 \\
\hline 80 & 3,728 & 97.2 & 14.6 & 111.8 & 6.7 & 7.7 & 63.4 & 105.8 & 106.7 & 77.6 & 39.4 \\
\hline 49 & 10,092 & 71.7 & 15.2 & 86.8 & 4.7 & 6.1 & 55.3 & 103.6 & 111.5 & 86.4 & 43.1 \\
\hline 36 & 738 & 66.9 & 7.8 & 74.8 & 8.5 & 16.1 & 45.9 & 101.6 & 86.2 & 60.8 & 37.8 \\
\hline 51 & 382 & 63.4 & 10.7 & 74.2 & 5.9 & 0.0 & 63.4 & 91.7 & 99.5 & 13.9 & 0.0 \\
\hline 53 & 1,124 & 57.3 & 14.7 & 72.0 & 3.9 & 0.0 & 58.9 & 95.1 & 90.8 & 47.5 & 11.0 \\
\hline 64 & 4,506 & 56.9 & 14.9 & 71.8 & 3.8 & 6.4 & 62.5 & 97.4 & 103.8 & 83.8 & 18.1 \\
\hline 82 & 5,968 & 64.7 & 2.8 & 67.4 & 23.5 & 9.9 & 62.1 & 91.3 & 88.6 & 75.7 & 34.3 \\
\hline 13 & 1,924 & 59.1 & 6.1 & 65.2 & 9.6 & 11.4 & 60.5 & 85.0 & 73.7 & 59.9 & 9.9 \\
\hline 10 & 6,981 & 57.3 & 5.3 & 62.6 & 10.8 & 7.3 & 57.9 & 67.7 & 55.8 & 44.4 & 16.9 \\
\hline 16 & 898 & 58.5 & 3.7 & 62.2 & 15.8 & 11.4 & 44.0 & 52.0 & 52.9 & 51.2 & 30.8 \\
\hline 63 & 370 & 55.2 & 5.2 & 60.3 & 10.7 & 2.3 & 45.4 & 78.4 & 96.1 & 67.7 & 51.5 \\
\hline 86 & 7,865 & 52.8 & 5.9 & 58.7 & 9.0 & 4.9 & 53.6 & 89.3 & 96.8 & 89.9 & 21.4 \\
\hline 29 & 2,423 & 51.5 & 3.3 & 54.8 & 15.8 & 10.8 & 54.5 & 62.5 & 53.3 & 30.7 & 28.3 \\
\hline 73 & 382 & 52.6 & 1.4 & 54.0 & 38.0 & 4.6 & 54.8 & 74.1 & 87.3 & 81.8 & 0.0 \\
\hline 41 & 2,248 & 51.6 & 2.1 & 53.7 & 24.5 & 4.2 & 43.8 & 66.5 & 71.7 & 74.4 & 47.1 \\
\hline 14 & 3,919 & 49.3 & 3.6 & 53.0 & 13.6 & 13.1 & 57.8 & 85.3 & 82.7 & 79.8 & 42.6 \\
\hline 33 & 304 & 48.7 & 3.9 & 52.6 & 12.4 & 0.0 & 21.9 & 40.1 & 55.0 & 55.8 & 16.3 \\
\hline 26 & 835 & 50.5 & 2.0 & 52.5 & 25.4 & 9.8 & 49.2 & 74.5 & 55.3 & 51.8 & 0.0 \\
\hline 28 & 1,747 & 50.6 & 1.7 & 52.3 & 30.6 & 9.9 & 51.2 & 64.4 & 54.0 & 35.5 & 7.7 \\
\hline 15 & 2,102 & 48.3 & 2.5 & 50.7 & 19.6 & 15.9 & 50.3 & 69.3 & 59.4 & 60.0 & 16.5 \\
\hline 70 & 421 & 47.0 & 3.6 & 50.6 & 13.1 & 7.9 & 35.1 & 65.5 & 86.7 & 58.5 & 0.0 \\
\hline 58 & 581 & 48.2 & 1.7 & 50.0 & 27.7 & 6.8 & 44.2 & 61.9 & 65.0 & 47.4 & 20.8 \\
\hline Brazil & 147,105 & 41.4 & 3.5 & 44.9 & 12.0 & 6.2 & 38.2 & 56.1 & 58.6 & 50.7 & 22.7 \\
\hline
\end{tabular}

NWR: non-work-related sickness benefit; PRR: prevalence ratio rates; WR: work-related sickness benefit.

* Rates: prevalence per 10,000 workers.

** Standard Industrial Classification of Economic Activities 2007 - SIC. http://www.ons.gov.uk/ons/guide-method/classifications/current-standard-classifica tions/standard-industrial-classification/index.html, accessed on 05/Dec/2011).

Note: 10: food products manufacturing; 13: textiles manufacturing ; 14: clothing manufacturing; 15: leather \& related products manufacturing; 16 : wood \& wood products manufacturing, except furniture; 26 : computer, electronic \& optical products manufacturing; 28 : machinery \& equipment manufacturing; 29: motor vehicle, trailers \& semi-trailers manufacturing; 33: repair \& installation of machinery \& equipment; 36: water collection, treatment \& supply; 37: sewage; 41: building industry; 49: land transport \& transport via pipelines; 51: air transport; 53: postal \& courier activities; 58: publishing activities; 60: programming \& broadcasting activities; 63: information service activities;64; financial service activities, except insurance \& pension funding; 70: activities of head offices; management consultancy activities; 73: advertising and market research; 80: security \& investigation activities;

82: office administrative, office support; 86: human health activities and; 87: residential care activities.

F40-F48) for each SIC. The results showed that over $40 \%$ of all sickness benefit claims among construction workers (SIC 41, 42 and 43) were due to mental disorders due to psychoactive substance use (F10-F19) compared to $16.3 \%$ among all SICs. The ICD-10 group schizophrenia, schizotypal and delusional disorders (F20-F29) showed the highest prevalence rates among forestry and logging workers and crop and animal production workers (15.7\% and $14.8 \%$, respectively). Mood (affective) disorders were more prevalent in female-dominated economic activities, such as health (65.6\%), clothing manufacturing (65.4\%) and education $(62.1 \%)$. The overall prevalence rate (among all workers) of ICD-group neurotic, stress-related and somatoform disorders (F40F48) was $22 \%$. The highest rates for this ICDgroup were observed among air transport work- 
Prevalence of sickness benefit claims due to mental disorders according to International Classification of Diseases, 10th Revision (ICD-10) group, age and sex. Brazil, 2008.

\begin{tabular}{|c|c|c|c|c|c|c|c|}
\hline \multirow[t]{3}{*}{ ICD-10 group } & \multicolumn{7}{|c|}{ Prevalence per 10,000 workers } \\
\hline & \multicolumn{6}{|c|}{ Age group (years) } & \multirow[t]{2}{*}{ Total claims } \\
\hline & $<20$ & $20-29$ & $30-39$ & $40-49$ & $50-59$ & $\geq 60$ & \\
\hline \multicolumn{8}{|l|}{ Total } \\
\hline F00-F09 & 0 & 0.2 & 0.6 & 0.9 & 1.4 & 1.5 & 0.6 \\
\hline F10-F19 & 1.6 & 8.2 & 8.6 & 7.6 & 6.2 & 2.9 & 7.4 \\
\hline F20-F29 & 0.6 & 2.8 & 4.4 & 4.7 & 4.1 & 1.8 & 3.5 \\
\hline F30-F39 & 2.9 & 18 & 28.9 & 32 & 28.9 & 12.5 & 23.3 \\
\hline F40-F48 & 1.3 & 8.4 & 12.9 & 12.7 & 9.7 & 3.6 & 9.9 \\
\hline MD & 6.5 & 38.2 & 56.1 & 58.6 & 50.7 & 22.7 & 45.1 \\
\hline \multicolumn{8}{|c|}{ Male } \\
\hline F00-F09 & 0 & 0.3 & 0.7 & 1.1 & 1.6 & 1.7 & 0.7 \\
\hline F10-F19 & 2.8 & 13.2 & 13.5 & 11.7 & 8.9 & 3.7 & 11.9 \\
\hline F20-F29 & 0.8 & 3.3 & 4.8 & 4.9 & 4.2 & 1.9 & 4 \\
\hline F30-F39 & 1.4 & 8.6 & 14.8 & 17.5 & 16.4 & 8.5 & 12.7 \\
\hline F40-F48 & 0.6 & 4.9 & 9.3 & 9.7 & 7.3 & 3 & 7.2 \\
\hline MD & 5.6 & 30.6 & 43.5 & 45.3 & 38.7 & 19.2 & 36.7 \\
\hline \multicolumn{8}{|c|}{ Female } \\
\hline F00-F09 & 0 & 0.2 & 0.4 & 0.7 & 1 & 1 & 0.4 \\
\hline F10-F19 & 0.1 & 0.7 & 0.9 & 0.9 & 0.7 & 0.4 & 0.8 \\
\hline F20-F29 & 0.2 & 1.9 & 3.7 & 4.4 & 3.9 & 1.4 & 3 \\
\hline F30-F39 & 5.1 & 32.2 & 51.2 & 55.9 & 54.6 & 25.6 & 42.9 \\
\hline F40-F48 & 2.3 & 13.7 & 18.7 & 17.7 & 14.7 & 5.4 & 15.4 \\
\hline MD & 7.7 & 49.7 & 76.2 & 80.6 & 75.4 & 33.9 & 63.5 \\
\hline
\end{tabular}

Note: F00-F09: organic, including symptomatic, mental disorders; F10-F19: psychoactive substance use;

F20-29: schizophrenia, schizotypal and delusional disorders; F30-F39: mood disorders; F40-F48: neurotic, stress-related and somatoform disorders; MD: mental and behavioural disorder.

ers (44\%), land transport workers $(35.5 \%)$ and workers involved in financial service activities (35\%)(data not shown).

\section{Discussion}

Our study shows that the cumulative prevalence rate of sickness benefit claims ( $>15$ days) due to mental disorders is $0.45 \%$, with large variability between economic activities, sex, age and work relatedness. The duration of claims varied substantially between ICD-10 group, with longest benefit duration occurring with organic mental disorders and schizophrenia, schizotypal and delusional disorders. Being male, aged over 40 years and receiving a monthly replacement sal- ary of at least R $\$ 1,000$ (Real - Brazilian currency) were more closely associated with sickness benefit claims (except for mental disorders due to psychoactive substance use) than being female, younger and low replacement salary. The lower prevalence of sickness benefits in Brazil compared to some European countries when considering similar or even longer inception points 4,9,10 could be explained by the large differences between the countries' social security systems and socioeconomic circumstances.

When comparing the proportion of overall sickness benefit claims due to mental disorders, we observed that the rate of mental disorderrelated claims in Brazil (10.7\% at more than 15 days) is lower than in other countries 25 such as the Netherlands $(19.2 \%,>28$ days) 4 and 
Table 3

Duration (days) of claims due to the main mental disorder groups (> 500 claims), by sex, age and salary replacement. Brazil, 2008.

\begin{tabular}{|c|c|c|c|c|c|c|c|}
\hline Variables & $\begin{array}{c}\text { F00-F10 } \\
\text { Median } \\
\text { (quartiles) * }\end{array}$ & $\begin{array}{c}\text { F10-F19 } \\
\text { Median } \\
\text { (quartiles) * }\end{array}$ & $\begin{array}{c}\text { F20-F29 } \\
\text { Median } \\
\text { (quartiles) * }\end{array}$ & $\begin{array}{c}\text { F30-F39 } \\
\text { Median } \\
\text { (quartiles) * }\end{array}$ & $\begin{array}{c}\text { F40-F48 } \\
\text { Median } \\
\text { (quartiles) * }\end{array}$ & $\begin{array}{c}\text { MD Total } \\
\text { Median } \\
\text { (quartiles) * }\end{array}$ & $\begin{array}{c}\text { MD claims } \\
n\end{array}$ \\
\hline \multicolumn{8}{|l|}{ Sex } \\
\hline Male & $104(66 ; 168)$ & $79(51 ; 115)$ & $97(65 ; 148)$ & $72(46 ; 106)$ & $65(41 ; 98)$ & $76(47 ; 113)$ & 71,195 \\
\hline Female & $86(53 ; 137)$ & $78(51 ; 116)$ & $93(62 ; 137)$ & $65(44 ; 96)$ & $58(36 ; 88)$ & $65(43 ; 97)$ & 75,910 \\
\hline \multicolumn{8}{|l|}{ Age (years) } \\
\hline$<40$ & $92(57 ; 151)$ & $81(54 ; 117)$ & $93(62 ; 137)$ & $64(43 ; 96)$ & $58(36 ; 88)$ & $68(45 ; 102)$ & 91,875 \\
\hline$\geq 40$ & $105(67 ; 166)$ & $76(46 ; 112)$ & $101(68 ; 154)$ & $71(46 ; 106)$ & $66(42 ; 100)$ & $74(46 ; 110)$ & 55,230 \\
\hline \multicolumn{8}{|c|}{ Salary $(\mathrm{R} \$)^{\star \star}$} \\
\hline$<1,000$ & $95(61 ; 152)$ & $80(53 ; 116)$ & $94(63 ; 139)$ & $65(44 ; 97)$ & $58(36 ; 88)$ & $69(45 ; 103)$ & 99,676 \\
\hline$\geq 1,000$ & $106(66 ; 171)$ & $77(46 ; 113)$ & $100(67 ; 154)$ & $70(46 ; 105)$ & $66(42 ; 99)$ & $72(46 ; 108)$ & 47,429 \\
\hline
\end{tabular}

* Quartiles one and three;

** Minimum wage in 2008 was $\mathrm{R} \$ 415.00$.

Note: F00-F09: organic, including symptomatic, mental disorders; F10-F19: psychoactive substance use; F20-29: schizophrenia, schizotypal and delusional disorders; F30-F39: mood disorders; F40-F48: neurotic, stress-related and somatoform disorders; MD: mental and behavioural disorder.

Table 4

Prevalence (per 10,000 workers) and duration (days) of disability claims due to mental disorder, according to age group and International Classification of Diseases, 10th Revision (ICD-10) code. Brazil, 2008.

\begin{tabular}{|c|c|c|c|c|c|c|c|c|c|}
\hline \multirow{2}{*}{$\begin{array}{l}\text { ICD-10 } \\
\text { code }\end{array}$} & \multicolumn{3}{|c|}{$<40$ years } & \multicolumn{3}{|c|}{$\geq \mathbf{4 0}$ years } & \multicolumn{3}{|c|}{ Total } \\
\hline & Claims & Prevalence & $\begin{array}{c}\text { Median } \\
\text { (quartiles) * }\end{array}$ & Claims & Prevalence & $\begin{array}{c}\text { Median } \\
\text { (quartiles) * }\end{array}$ & Claims & Prevalence & $\begin{array}{c}\text { Median } \\
\text { (quartiles) * }\end{array}$ \\
\hline MD & 91,875 & 42.2 & $68(45 ; 102)$ & 55,230 & 58.1 & $74(46 ; 110)$ & 147,105 & 45.1 & $70(45 ; 105)$ \\
\hline F32 & 31,126 & 14.3 & $61(40 ; 92)$ & 19,163 & 20.1 & $68(46 ; 102)$ & 50,289 & 15.4 & $64(43 ; 96)$ \\
\hline F41 & 12,514 & 5.8 & $56(35 ; 84)$ & 6,994 & 7.4 & $64(40 ; 96)$ & 19,508 & 6.0 & $60(37 ; 90)$ \\
\hline F33 & 7,463 & 3.4 & $68(46 ; 100)$ & 7,061 & 7.4 & $75(47 ; 109)$ & 14,524 & 4.5 & $72(46 ; 105)$ \\
\hline F19 & 9,773 & 4.5 & $85(60 ; 120)$ & 1,451 & 1.5 & $90(61 ; 123)$ & 11,224 & 3.4 & $86(60 ; 121)$ \\
\hline F31 & 5,876 & 2.7 & $76(48 ; 110)$ & 3,628 & 3.8 & $79(51 ; 117)$ & 9,504 & 2.9 & $77(49 ; 113)$ \\
\hline F43 & 5,578 & 2.6 & $60(37 ; 92)$ & 3,430 & 3.6 & $70(44 ; 107)$ & 9,008 & 2.8 & $64(39 ; 97)$ \\
\hline F10 & 3,539 & 1.6 & $75(46 ; 109)$ & 5,006 & 5.3 & $71(42 ; 108)$ & 8,545 & 2.6 & $72(44 ; 108)$ \\
\hline $\mathrm{F} 20$ & 2,850 & 1.3 & $105(73 ; 162)$ & 1,766 & 1.9 & $113(78 ; 176)$ & 4,616 & 1.4 & $108(76 ; 168)$ \\
\hline F14 & 3,092 & 1.4 & $79(54 ; 111)$ & 376 & 0.4 & $90(60 ; 119)$ & 3,468 & 1.1 & $80(55 ; 112)$ \\
\hline F29 & 1,808 & 0.8 & $90(60 ; 131)$ & 1,142 & 1.2 & $99(64 ; 147)$ & 2,950 & 0.9 & $93(61 ; 137)$ \\
\hline $\mathrm{F} 40$ & 1,312 & 0.6 & $62(39 ; 91)$ & 711 & 0.7 & $66(44 ; 96)$ & 2,023 & 0.6 & $63(40 ; 92)$ \\
\hline F23 & 1,240 & 0.6 & $78(49 ; 112)$ & 554 & 0.6 & $81(52 ; 122)$ & 1,794 & 0.6 & $78(50 ; 117)$ \\
\hline
\end{tabular}

* Quartiles 1 and 3 .

Note: F10: use of alcohol; F14: use of cocaine; F19: multiple drug use; F20: schizophrenia; F23: unspecified nonorganic psychosis; F29: unspecified nonorganic psychosis; F31: bipolar affective disorders; F32: depressive episode; F33: recurrent depressive episode; F40: phobic anxiety disorders; F41: other anxiety disorders; F43: reaction to severe stress and; MD: mental and behavioural disorders. 
Table 5

Duration of claims due to mental disorders and ratios between economic activities *. Brazil, 2008.

\begin{tabular}{|c|c|c|c|c|c|c|}
\hline \multirow[t]{2}{*}{ SIC 2007 division } & \multirow{2}{*}{$\begin{array}{l}\text { Duration (in days) } \\
\text { Median }\end{array}$} & \multicolumn{2}{|c|}{ Quartile } & \multicolumn{3}{|c|}{ Ratio * } \\
\hline & & $25 \%$ & $75 \%$ & $50 \%$ & $25 \%$ & $75 \%$ \\
\hline 41 & 81 & 55 & 121 & 1.35 & 1.62 & 1.26 \\
\hline 80 & 79 & 50 & 121 & 1.32 & 1.47 & 1.26 \\
\hline 51 & 78 & 55 & 106 & 1.30 & 1.62 & 1.10 \\
\hline 49 & 77 & 48 & 117 & 1.28 & 1.41 & 1.22 \\
\hline 37 & 77 & 46 & 117 & 1.28 & 1.35 & 1.22 \\
\hline 70 & 76 & 46 & 107 & 1.27 & 1.35 & 1.11 \\
\hline 58 & 75 & 46 & 110 & 1.25 & 1.35 & 1.15 \\
\hline 28 & 71 & 46 & 106 & 1.18 & 1.35 & 1.10 \\
\hline 47 & 71 & 46 & 105 & 1.18 & 1.35 & 1.09 \\
\hline 33 & 69 & 46 & 99 & 1.15 & 1.35 & 1.03 \\
\hline 16 & 69 & 46 & 105 & 1.15 & 1.35 & 1.09 \\
\hline 87 & 69 & 44 & 107 & 1.15 & 1.29 & 1.11 \\
\hline 60 & 68 & 44 & 102 & 1.13 & 1.29 & 1.06 \\
\hline 82 & 68 & 43 & 102 & 1.13 & 1.26 & 1.06 \\
\hline 26 & 68 & 41 & 102 & 1.13 & 1.21 & 1.06 \\
\hline 63 & 67 & 44 & 98 & 1.12 & 1.29 & 1.02 \\
\hline 86 & 66 & 44 & 100 & 1.10 & 1.29 & 1.04 \\
\hline 64 & 66 & 43 & 98 & 1.10 & 1.26 & 1.02 \\
\hline 10 & 65 & 45 & 98 & 1.08 & 1.32 & 1.02 \\
\hline 13 & 65 & 46 & 98 & 1.08 & 1.35 & 1.02 \\
\hline 85 & 65 & 43 & 98 & 1.08 & 1.26 & 1.02 \\
\hline 29 & 65 & 40 & 101 & 1.08 & 1.18 & 1.05 \\
\hline 73 & 65 & 39 & 98 & 1.08 & 1.15 & 1.02 \\
\hline 14 & 63 & 45 & 95 & 1.05 & 1.32 & 0.99 \\
\hline 53 & 62 & 41 & 91 & 1.03 & 1.21 & 0.95 \\
\hline 15 & 61 & 42 & 91 & 1.02 & 1.24 & 0.95 \\
\hline 36 & 60 & 34 & 96 & 1.00 & 1.00 & 1.00 \\
\hline
\end{tabular}

* Standard Industrial Classification of Economic Activities 2007 - SIC. http://www.ons.gov.uk/ons/guide-method/classifica tions/current-standard-classifications/standard-industrial-classification/index.html, accessed on 05/Dec/2011.

** Ratio between duration for each SIC and the lowest duration (SIC division 36).

Note: 10: food products manufacturing; 13 : textiles manufacturing ; 14 : clothing manufacturing; 15 : leather \& related products manufacturing; 16: wood \& wood products manufacturing, except furniture; 26: computer, electronic \& optical products manufacturing; 28: machinery \& equipment manufacturing; 29: motor vehicle, trailers \& semi-trailers manufacturing; 33: repair \& installation of machinery \& equipment; 36: water collection, treatment \& supply; 37: sewage; 41: building industry; 49: land transport \& transport via pipelines; 51: air transport; 53: postal \& courier activities; 58: publishing activities; 60: programming \& broadcasting activities; 63: information service activities;64; financial service activities, except insurance \& pension funding; 70: activities of head offices; management consultancy activities; 73: advertising and market research; 80: security \& investigation activities; 82: office administrative, office support; 86: human health activities and; 87: residential care activities.

Norway 9 (16.8\%, > 14 days). However, rates are similar to those in France, where for all claims over a three-year period the rate of absence $>$ seven days among women and men was $13.8 \%$ and $7.3 \%$, respectively 26 . Considering that in general, mental disorders lead to long-lasting claims, the longer inception point of the Dutch study could have increased the contribution of mental disorders to long-term disability when compared to our results. However, when compared to the Norwegian study 9 , which used a similar inception point to our study, the differences could be due to socioeconomic differences and differences in the welfare system, which could contribute to 
the higher frequency and duration of claims. In Brazil, wage replacement is calculated by averaging salary contributions and excluding the lowest $20 \%$ of monthly salaries and does not include indirect salary (such as paid overtime) and therefore the amount of salary received can be substantially reduced. Considering that the majority of the population on sickness benefits receive less than $\mathrm{R} \$ 1,000.00$ ( $\approx$ USD550.00) per month (data not shown), the implication is that some people cannot afford to be on sickness benefit 27 because finances take precedence over diagnosis. In Norway, workers receive $100 \%$ coverage during the first year of work disability ${ }^{9}$, which would generally prevent the sick worker from having to make this kind of choice.

After adjusting for sex and age, sickness benefit claims vary substantially between SIC for both non-work and work-related claims. Some European studies have corroborated this variability between economic sectors or occupational categories, but without considering work-relatedness $2,4,12,13$. In the Netherlands, claims in sectors such as education, financial services and healthcare were higher than in other sectors 4 . In France, the highest work disability/sickness absence rates due to mental disorders were found in lower skilled categories such as office and manual workers 12 .

The large variation in PRR between non-work and work-related sickness benefits due to mental disorders according to SIC (range: 3.6 to 38.0 ) demands some explanation. The 26 SICs with the highest rates of mental disorder benefits, adjusted for sex and age and the PRR analysis of nonwork-related and work-related benefits, showed that six of the nine SICs with the highest prevalence rates were also those with the highest confirmation rates of work-relatedness. Exceptions were the two local public sectors (mixed capital government controlled) represented by sewage and water catchment, treatment and supply (15.5 and 8.5, respectively) and programming and broadcasting (9.7). Compared to other top SICs, the medium to low confirmation of work-relatedness in these economic sectors could be due to two factors. The first applies to all three sectors mentioned above and is related to the weakness of worker unionization and the consequent lack of union pressure to focus on health and safety. The second factor is more specific to public sector workers and is related to higher job stability and a potentially more tolerant management than in strictly private sectors; the contribution of state and municipal workers to sickness absence is significantly greater than other sectors 28,29 .

The high prevalence of sickness benefit claims due to mental disorders found among programming and broadcasting activities workers may be associated with work factors such as high levels of time pressure, work content and excessive work demands 13,30, while the low level of work-related sickness benefit claims due to mental disorders among workers in this group may be explained by the weakness of worker unionization. It might also be due to a perception by health professionals, especially non-occupational physicians, that programming and broadcasting is glamorous, leading them to underestimate occupational hazards. However, the data shows the magnitude of sickness benefit due to mental disorders in this understudied population. More research is needed to understand the risk factors involved in certain economic activities, particularly sewerage, residential care and programming and broadcasting, which contribute to the high rates of sickness benefit claims. The higher prevalence of sickness benefit claims for mental disorders in general and diagnostic groups, such as mood disorders and neurotic, stress-related and somatoform disorders, particularly among women, found by our study, have been corroborated by several authors 2,4,6,10,12,16. However, a review of sickness absence and psychiatric disorders found limited evidence to support this gender difference. The review pointed out that the gender difference disappears when the considered outcome is the duration of the disability claim ${ }^{2}$. The higher crude rates of sickness benefits related to mental disorders among women found by our study are corroborated by a study of municipal workers in Finland, where females presented $56 \%$ higher sickness-absence rates due to mental disorders ( $>2$ weeks) than males; however this gender difference decreased to $17 \%$ when adjusted for occupation and workplace 16 . This difference between men and women seems to be determined more by gender roles and work conditions than by sex. Typical negative factors associated with women's employment include: lower salaries; little autonomy and repetitive and monotonous work; women remain responsible for burdensome domestic work and the children; poverty; and being subjected to sexual harassment and violent abuse. These factors, together with different health-seeking behaviour may largely explain the difference in women's sickness absence due to mental health and particularly depression and anxiety 2,4,6,9,12,16.

Our results showed that the rates of sickness benefit claims increased with age up to the age of 49 , after which point the rate begins to decline. The different pattern found in programming and broadcasting workers can be explained by the ratio of men to women (2.2:1) and the younger average age $(29.1 \%<30$ years $)$, which indicates that 
older workers may be selected out of this economic activity at a relatively young age 4,6,9,16.

The low rates of work-relatedness found in our study may be partially explained by working conditions and, more specifically, psychosocial constraints. Despite evidence presented by several studies showing the association between working conditions and mental health, the specific effect attributable to each occupation remains uncertain 12 .

Our results on the duration of claims showed that the median duration of benefits due to mental disorders in general (70 calendar days) is shorter than the median presented among Norwegian workforce 9 . Both studies (ours and the Norwegian) agreed that there are important differences between sex, age groups and diagnostic groups of mental disorders. Men remained on benefits longer than women for all mental disorder diagnostic groups 9 . It should be noted that in general older men received greater benefits since average salaries in this group were greater and this may confound the findings.

Duration of claims was greatest among construction workers. This result is somewhat different to that presented by a Dutch study on mental health sickness absence 4 . This study showed that this category of workers presented a smaller percentage of sick days (16\%) than economic activities with direct contact with people such as education (39\%), financial services (31\%) and health care $(30 \%)$. Nevertheless, this difference could be due to the use of different calculating methods (median duration of claims versus \% of sickleave days). More recently, results from a study of a different population from the same country 31 showed that high physical job demands, moderate to severe depressive symptoms and older age were associated with longer sickness absence duration. It is well known that violence and fear constitute important risk factors for several mental disorders, and violence at work may contribute to increased prevalence and severity of a mental disorder 32,33 resulting in longer duration of disability claims. Findings from the 2009/2010 British Crime Survey 32 suggest that workers in protective services face a major risk of violence at work (9\%) principally from assault (8.4\%). This survey also confirmed that health professionals face a high risk of threats in the workplace (3.4\%). Any comparison to the literature regarding the prevalence of work disability claims and duration should be made considering that the results presented in this study refer only to claims by employed workers on work disability benefits. Employed workers are eligible to claim benefit after being off work due to sickness for 15 consecutive days. This implies that only moder- ate to severe health conditions are considered for claims. Authors highlight the difference between illness and sickness. The ratio between these two concepts varies from 11, among male workers, to 18 among females 4 . It is expected that morbidity due to mental and behavioural disorders is more prevalent among the general population than among employed workers 4 .

Longer sickness benefit duration related to claims due to mental disorders among construction workers could be associated with the high prevalence of mental and behavioural disorders due to psychoactive substance use in this SIC. This diagnosis normally demands lengthy treatment. High physical work load is another factor associated with longer sickness benefit duration 31, which could also contribute to the longer duration of work disability found among construction workers.

The high prevalence of mental disorders due to psychoactive substances use among construction workers is a well recognized phenomenon. In the U.S. National Survey on Worker Drug Use and Health 34 , construction workers presented the highest rate of past month heavy alcohol use (15.9\%) and the second highest rate of past month illicit drug use (13.7\%) among full-time workers aged 18 to 64 years. Another factor associated to alcohol consumption is low socioeconomic status, where low income is often a risk factor for increased alcohol consumption or where the income of people with drug and alcohol problems and other mental disorders, such as schizophrenia, may be lower due to employment limitations imposed by the mental disorder 35 .

The ICD-group mood disorders accounted for the highest proportion of mental disorder claims, irrespective of age, sex and SIC (except construction activities). The high proportion of claims related to this ICD-group in femaledominated SICs is supported by other studies showing a higher prevalence of depression among women than among men, regardless of economic activity $7,13,17$.

The high proportion ( $\geq 35 \%$ ) of work disability claims due to mental disorders related to the ICD-group neurotic, stress-related and somatoform disorders (F40-F48) among air transport, land transport and financial service workers could be associated with several risk factors presented by these activities, among which fear at work caused by the risk of accidents and violence may be one of the most important. A study of minor psychiatric disorders among truck drivers in Brazil and the related stress factors in this category showed that fear of being robbed (64.4\%) and having a road traffic accident (50.7\%) were the most important causes of fear at work, 
contributing to increased stress levels. Other statistically significant factors referred to by drivers as stressful conditions were long journeys, heavy traffic and high job demand, combined with low job autonomy and weak social support 36 .

Financial services is probably the activity that has been most affected by technological and structural changes over the past two decades. The International Labour Organization (ILO) reports that factors such as mergers and acquisitions, globalization, compliance issues and technological developments have introduced important changes in work activities for financial service workers. These changes lead to several concerns, including increasing time pressure, excessive work demands, role conflict and increased violence and stress at work. These factors have led to job insecurity, increasing demands and higher performance which in turn contribute to mental and physical disorders, in particular those associated with stress 33 .

The general limitations of our study stem from the work population used. Data from the SUB is limited to employed workers from the private sector. It is possible that the health conditions of workers in the informal sector (non-registered workers) are worse than those of employed workers and therefore this data should only be considered in the context of the study population.

The use of job contracts as the denominator for determining prevalence is another limitation of this study, since in sectors such as health and education many workers are likely to have more than one job contract. This limitation leads to an overestimation of the number of workers and leads to a decrease in prevalence rates.

Our study analysed one of the largest databases based on social security data on sickness benefit claims due to mental disorders. This database is controlled solely by the National Social Security Institute, which follows standard parameters of benefit concession, and includes both work-related and non-work-related sickness benefits claims.

This study adds insight into the rates and duration of sickness benefit claims due to mental disorders from a developing country perspective which was previously lacking in the literature. Overall, the rates and duration of sickness absence/work disability benefits due to mental disorders in Brazil are considerably lower than in developed countries, probably due to underreporting because of socioeconomic differences and the type of sample population (only employed workers). With respect to sickness benefits, those who claim are often only the tip of the iceberg, particularly in Brazil. In developing countries in particular, a number of underlying factors affect the claims process for sickness benefit, including job insecurity, short job duration and economic consequences of claiming benefit. These factors are less favourable in Brazil than in Western European countries 4,6,9,10,27 and might explain differences in results between these respective regions. .

Despite potential under-claiming of sickness benefits, policy makers, healthcare professionals, and the social security system should be aware that mental disorders are an important cause of sickness benefit claims with a wide variation in prevalence and duration according to economic activity, age, work-relatedness and diagnoses, suggesting that working conditions are an important factor warranting further investigation. Attention should be given to productivity loss at work and certain potential filters 37 (fear of job loss, monetary safety incentive system, weak labour unions) which contribute to the underestimation of sickness benefit claims. Taking the natural history of mental disorders into account, one is left to believe that low rates of sickness benefit claims may later result in extended sickness absences or even higher permanent work disability rates. The identification of higher risk activities may encourage health and labour authorities and employers to concentrate investments in preventive measures. Future research should be undertaken to investigate the long-term consequences of early and recurrent episodes of mental disorders. 


\section{Resumo}

Este estudo visa determinar a prevalência e a duração dos benefícios auxílio-doença devidos à doença mental e sua associação com atividade econômica, sexo, idade, relação com o trabalho, e reposição salarial. Estudaram-se os benefícios auxílio-doença por doença mental concedidos no Brasil em 2008. Analisou-se a associação entre benefícios auxílio-doença e sexo, idade, atividade econômica, relação com o trabalho e reposição salarial. Doença mental representou $10.7 \%$ do total de benefícios auxílio-doença em 2008, com prevalência de 45,1/10 mil trabalhadores. A prevalência e a duração dos benefícios auxílio-doença foram maiores e mais longos entre trabalhadores $\geq 40$ anos de idade; mulheres tiveram prevalência 73\% maior do que homens, mas com menor duração. As prevalências variaram amplamente entre atividade econômica, sendo esgoto, saúde da família e rádio e televisão aquelas com as maiores taxas. A relação com o trabalho foi caracterizada em 8,5\% dos benefícios. Doença mental mostrou baixa relação com o trabalho, mas com ampla variação na prevalência e na duração dos benefícios auxílio-doença em relação à idade, sexo e atividade econômica, sugerindo que as condições de trabalho constituem fator mais importante para incapacidade do que o presumido.

Transtornos Mentais; Previdência Social; Depressão; Trabalho

\section{References}

1. Moncrieff J, Pomerleau J. Trends in sickness benefits in Great Britain and the contribution of mental disorders. J Public Health Med 2000; 22:59-67.

2. Hensing G, Wahlstrom R. Sickness absence and psychiatric disorders. Scan J Public Health 2004; 32 Suppl 63:152-80.

3. Virtanen M, Koskinen S, Kivimäki M, Honkonen T, Vahtera J, Ahola K, et al. Contribution of non-work and work-related risk factor to the association between income and mental disorders in a working population: the Health 2000 Study. Occup Environ Med 2008; 65:171-8.

4. Roelen CAM, Koopmans PC, Hoedeman R, Bültmann U, Groothoff JW, van der Klink JJL. Trends in the incidence of sickness absence due to common mental disorders between 2001 and 2007 in the Netherlands. Eur J Public Health 2009; 19:625-30.

\section{Contributors}

A. Barbosa-Branco participated in all stages of research and wrote the draft of this manuscript. U. Bültmann participated in data analysis and writing this manuscript. I. Steenstra participated in all stages of the development of this research.

\section{Acknowledgments}

The authors express their gratitude to Dr. Paulo Rogério Albuquerque Oliveira for his generous help in obtaining the databases, and to Victoria Pennick for her assistance in editing the manuscript.
5. Wallman T, Wedel H, Palmer E, Rosengren A, Johansson S, Eriksson H, et al. Sick-leave track records and other potential predictors of a disability pension. A population based study of 8,218 men and women followed for 16 years. BMC Public Health 2009; 9:104.

6. Hensing G, Andersson L, Brage S. Increase in sickness absence with psychiatric diagnosis in Norway: a general population-based epidemiologic study of age, gender and regional distribution. BMC Med 2006; 4:19.

7. Bültmann U, Christensen KB, Burr H, Lund T, Rugulies R. Severe depressive symptoms as predictor of disability pension: a 10-year follow-up study in Denmark. Eur J Public Health 2008; 18:232-4. 
8. Eaton WW, Martins SS, Nestadt G, Bienvenu OJ, Clarke D, Alexandre P. The burden of mental disorders. Epidemiol Rev 2008; 30:1-14.

9. Nystuen P, Hagen KB, Herrin J. Mental health problems as a cause of long-term sick leave in the Norwegian workforce. Scand J Public Health 2001; 29:175-82.

10. Sandanger I, Nygård JF, Brage S, Tellnes G. Relation between health problems and sickness absence: gender and age differences: a comparison of lowback pain, psychiatric disorders, and injuries. Scand J Public Health 2000; 28:244-52.

11. Schopper D, Pereira J, Torres A, Cuende N, Alonso M, Baylin A, et al. Estimating the burden of disease in one Swiss canton: what do disability adjusted life years (DALY) tell us? Int J Epidemiol 2000; 29:871-7.

12. Cohidon C, Imbernon E, Goldberg M. Prevalence of common mental disorders and their work consequences in France, according to occupational category. Am J Ind Med 2009; 52:141-52.

13. Wieclaw J, Agerbo E, Mortensen PB, Burr H, Tuchsen F, Bonde JP. Psychosocial working conditions and the risk of depression and anxiety disorders in the Danish workforce. BMC Public Health 2008; 8:280.

14. Moreau M, Valente F, Mak R, Pelfrene E, De Smet P, De Backer G, et al. Occupational stress and incidence of sick leave in the Belgian workforce: the Belstress Study. J Epidemiol Community Health 2004; 58:507-16.

15. Muntaner C, Eaton WW, Miech R, O'Campo P. Socioeconomic position and major mental disorders. Epidemiol Rev 2004; 26:53-62.

16. Laaksonen M, Mastekaasa P, Mirtikainen P, Rahkonen O, Piha K, Lahelma E. Gender differences in sickness absence - the contribution of occupation and workplace. Scand J Work Environ Health 2010; 36:394-403.

17. Wang J, Schmitz N, Dewa C, Stanfeld S. Changes in perceived job strain and the risk of major depression: results from a population-based longitudinal study. Am J Epidemiol 2009; 169:1085-91.

18. Bültmann U, van Amelsvoort LGPM, van den Brandt PA, Kasl SV. Differences in fatigue and psychological distress across occupations: results from the Maastricht Cohort Study of Fatigue at Work. J Occup Environ Med 2001; 43:976-83.

19. Santos EG, Siqueira MM. Prevalência dos transtornos mentais na população adulta brasileira: uma revisão sistemática de 1997 a 2009. J Bras Psiquiatr 2010; 59:238-46

20. Yassi A, Gilbert M, Cvitkovich Y. Trends in injuries, illnesses, and policies in Canadian healthcare workplaces. Can J Public Health 2005; 96:333-9.

21. Lippel K, Sikka A. Access to workers' compensation benefits and other legal protections for work-related mental health problems: a Canadian overview. Can J Public Health 2010; 101 Suppl 1:S16-22.

22. Netterstrøm B, Conrad N, Beck P, Fink P, Rugulies $\mathrm{R}$, Stanfeld $\mathrm{S}$. The relation between work-related psychosocial factors and the development of depression. Epidemiol Rev 2008; 30:118-32.
23. Bonde JPE. Psychosocial factors at work and risk of depression: a systematic review of the epidemiological evidence. Occup Environ Med 2008; 65: 438-45.

24. Brasil. Decreto-Lei no. 5.452 de 1o de maio de 1943, aprova a consolidação das leis do trabalho. Diário Oficial da União 1943, 9 ago.

25. Barbosa-Branco A, Souza WR, Steenstra IA. Incidence of work and non-work related disability claims in Brazil. Am J Ind Med 2011; 54:858-71.

26. Ferrie JE, Vahtera J, Kavimäki M, Westerlund H, Melchior M, Alexanderson K, et al. Diagnose-specific sickness absence and all cause mortality in the GAZEL study. J Epidemiol Community Health 2009; 63:50-5.

27. Piha K, Laaksonen M, Martikainen P, Rahkonen O, Lahelma E. Interrelationships between education, occupational class, income and sickness absence. Eur J Public Health 2009; 20:276-80.

28. Morse T, Dillon C, Kenta-Bibi E, Weber J, Diva U, Warren N, et al. Trends in work-related musculoskeletal disorder reports by year, type, and industrial sector: A capture-recapture analysis. Am J Ind Med 2005; 48:40-9.

29. Lund T, Christensen KB, Vaez M, Labriola M, Josephson M, Villadsen E, et al. Differences in sickness absence in Sweden and Denmark: the cross national HAKNAK study. Eur J Public Health 2008; 19:343-9.

30. Giga SI, Hoel H, Cooper CL. Violence and stress at work in the performing arts and in journalism. Geneva: International Labour Organization; 2003. (Working Paper, 201).

31. Vlasveld MC, van der Feltz-Cornelis CM, Bültmann U, Beekman ATF, van Mechelen W, Hoedeman R, et al. Predicting return to work in workers with all-cause sickness absence greater than 4 weeks: a prospective cohort study. J Occup Rehabil 2012; 28:118-26.

32. Packham C. Violence at work: findings from the 2009/2010 British Crime Survey. London: Health and Safety Executive Home Office; 2011.

33. Giga SI, Hoel H. Violence and stress at work in financial services. Geneva: International Labour Organization; 2003. (Working Paper, 210).

34. Substance Abuse and Mental Health Services Administration, Office of Applied Studies. The NSDUH report: worker substance use by industry category. Rockville: Office of Applied Studies; 2007.

35. Hwang SW, Agha MM, Creatore MI, Glazier RH Age-and sex-specific income gradients in alcoholrelated hospitalization rates in an urban area. Ann Epidemiol 2005; 15:56-63.

36. Ulhôa MA, Marqueze EC, Lemos LC, Silva LG, Silva AA, Nehme P, et al. Distúrbios psíquicos menores e condições de trabalho em motoristas de caminhão. Rev Saúde Pública 2010; 44:1130-6.

37. Azaroff LS, Levenstein C, Wegman DH. Occupational injury and illness surveillance: conceptual filters explain underreporting. Am J Public Health 2002; 92:1421-9.

Submitted on 19/Mar/2012

Final version resubmitted on 21/Jun/2012

Approved on 18/Jul/2012 